\title{
Rapid cytochemical demonstration of cytochrome oxidase activity in pathogenic bacteria
}

\author{
M R Barer, P J Marsh
}

\begin{abstract}
Aims: To develop and assess a cytochemical technique for the light microscopical detection of oxidase activity in pathogenic bacteria.

Methods: Live bacterial cells were deposited on to aminopropylsilane treated glass coverslips by centrifugation, dried, then reacted with either $1 \%$ (w:v) n,n,n',n'-tetramethyl-p-phenylene diamine (TPD) or $5 \mathrm{mM}$ diaminobenzidine (DAB) at $37^{\circ} \mathrm{C}$. The preparations were mounted in $50 \%$ glycerol and assessed by brightfield microscopy. An optimised DAB procedure (5 minutes of drying at $37^{\circ} \mathrm{C}$ and 10 minutes of reaction time) was applied to 44 strains of organisms commonly associated with infections in man and to two fresh positive blood culture containing Gram negative bacilli.
\end{abstract}

Results: TPD gave no discernible localised reaction product and was not investigated further. With DAB, oxidase positive cells (brown) were clearly differentiated from oxidase negative cells (colourless) even in mixed preparations. The DAB technique correctly assigned 18 oxidase positive isolates (seven genera), 26 oxidase negative isolates (eight genera), and the organisms present in the two freshly positive blood cultures to their appropriate oxidase reactivity as defined by the standard macroscopic TPD technique.

Conclusions: The cytochemical reaction seems to be a reliable indicator of the macroscopic oxidase test. It permits determination of oxidase reactivity at an early stage in the assessment of clinical material when infecting organisms can be demonstrated by microscopy. Further development of this and related cytochemical techniques could permit the provision of microbiological information that would be relevant to patient management, well in advance of conventional techniques.

The oxidase test is a key step in determining the taxonomic status and identity of pathogenic bacteria. ${ }^{12}$ The reaction is conventionally done at the macroscopic level using colonies growing on agar media. Knowledge of the oxidase reactivity of organisms present in clinical specimens before they have been fully identified can have a profound effect on patient management. For example, a positive test can exclude the possibility that an isolate is a Salmonella sp or support a presumptive identification of Pseudomonas sp.

A technique capable of demonstrating oxidase reactivity at a time when the organisms concerned are only detectable by microscopy could provide clinically valuable information earlier than conventional methods. It could also facilitate taxonomic studies on slow growing organisms. The recent development of a method for attaching viable bacteria to optical quality glass without damage and subsequent microscopic demonstration of $\beta$-galactosidase reactivity in the immobilised cells ${ }^{34}$ led us to examine the possibility of developing a cytochemical oxidase procedure applicable to pathogenic bacteria within the context of a routine diagnostic laboratory.

Cytochemical demonstration of oxidase has been achieved in bacteria using the Nadi Reagent. ${ }^{5}$ Such mixtures of aryl amines and electron donors have been used extensively for histological work but the procedures generally require total incubation times in excess of 30 minutes, ${ }^{67}$ and there is some doubt about the efficiency of the electron donors used. ${ }^{8}$ In contrast, diaminobenzidine (DAB) has been shown to be valuable for the histochemical demonstration ${ }^{9}$ and quantitation of cytochrome oxidase with incubation times under 15 minutes. ${ }^{8}$ We report results obtained when $\mathrm{DAB}$ and the standard macroscopic reagent $\mathrm{n}, \mathrm{n}, \mathrm{n}^{\prime}, \mathrm{n}^{\prime}$-tetramethyl-p-phenylene diamine (TPD) were used for the cytochemical demonstration of oxidase activity in clinical isolates of pathogenic bacteria.

\section{Methods}

Strains examined included laboratory controls and isolates identified to a level appropriate to their medical context by standard clinical laboratory methods. ${ }^{12}$ Clinical isolates were stored on nutrient agar slopes and laboratory strains were maintained by weekly subculture on blood or chocolate agar (Oxoid). Broth cultures were prepared in Todd Hewitt broth (Oxoid).

Bacterial suspensions were prepared directly from agar or by dilution of three to five hour broth cultures in sterile distilled water to a density not greater than a McFarland No 1 standard (about $3 \times 10^{8}$ cells $\mathrm{ml} / \mathrm{l}$ ). Blood cultures were examined neat and at 1 in 4 and 1 in 10 dilutions. Bacteria were immobilised on glass coverslips by the APS-centrifugation technique. ${ }^{3}$ Briefly, $22 \times 64 \mathrm{~mm}$ glass coverslips $(\mathrm{BDH})$ which had been treated with 3- 

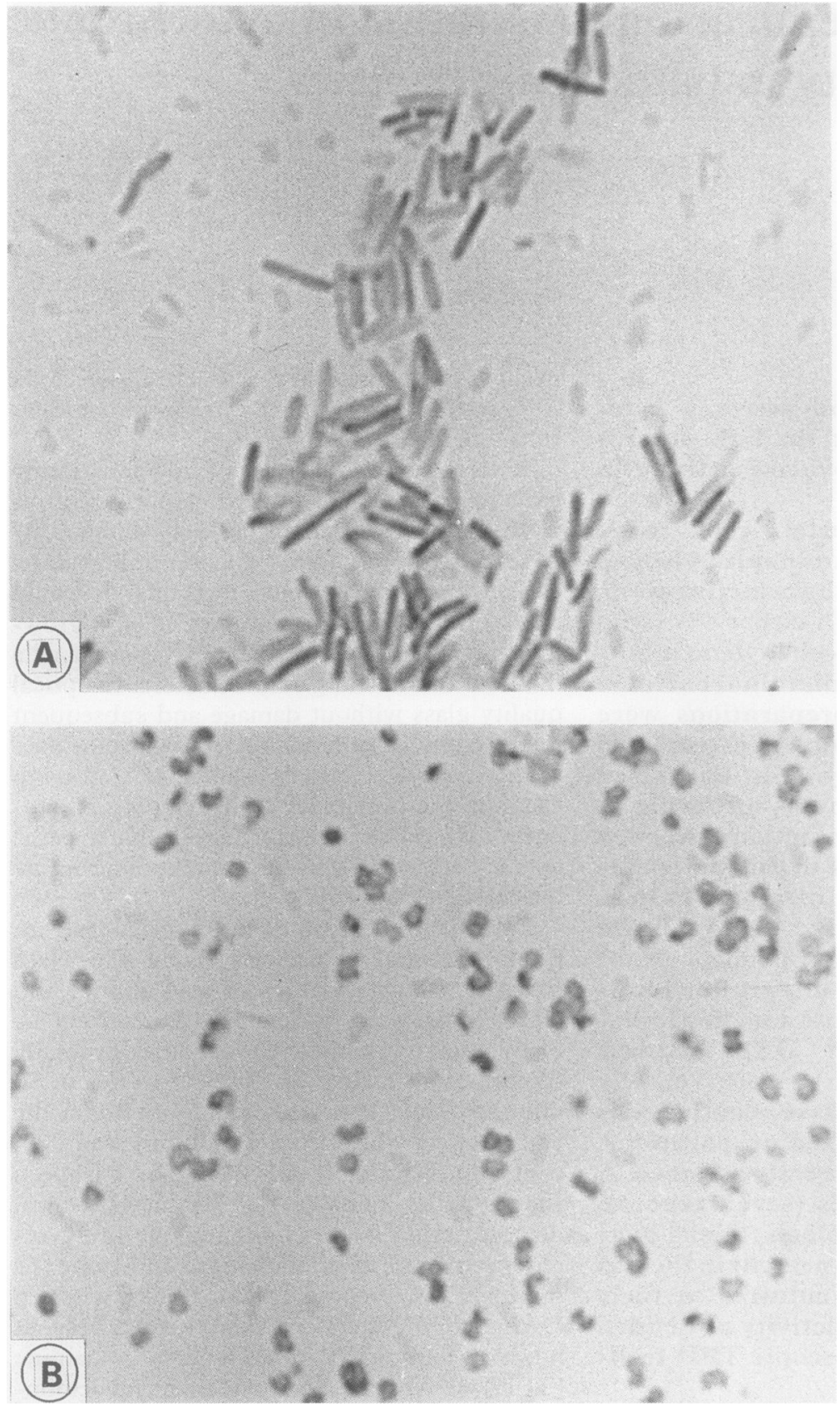

Figure 1 Mixtures of oxidase positive and negative organisms stained by the $D A B$ reaction. ( $A$ ) Acinetobacter anitratus (unstained coccobacilli), and Pseudomonas aeruginosa (stained bacilli). (B) Acinetobacter anitratus and Neisseria meningitidis (stained diplococci). Note that the unstained bacteria are very faint on these photomicrographs. They can be clearly discerned by phase contrast microscopy.

aminopropyltriethoxysilane ${ }^{10}$ (APS) (Sigma) were assembled into Bellco microslide chambers (Arnold Horwell, London). These provide a 10 chamber (each $2 \mathrm{~mm}$ radius $\times 12 \mathrm{~mm}$ deep) superstructure which permits the attachment of different organisms and subsequently the application of different staining processes to separate cell monolayers on the same coverslip. Aliquots of the suspensions $(50 \mu \mathrm{l})$ were added to the chambers and cells deposited onto the APS treated surface by subjecting the entire assembly to centrifugation at $1000 \times g$ for two minutes. The cell suspension medium was removed prior to further processing.

Oxidase was detected macroscopically using TPD. ${ }^{2}$ Reactions for microscopic examination were either done by adding $50 \mu$ l of the reaction mixture to the immobilised cells in the microslide chambers directly after removal of the suspension medium or after a drying step $\left(37^{\circ} \mathrm{C}\right)$. TPD ( $\left.1 \% \mathrm{w}: \mathrm{v}\right)$ was prepared in distilled water and DAB (5 $\mathrm{mM})$ in $0.1 \mathrm{M}$ Sorensen's phosphate buffer ( $\mathrm{pH} 7 \cdot 4$ ). Drying and reaction times (both at $37^{\circ} \mathrm{C}$ ) were as stated in the text. TPD was made up just before use while DAB was prepared at working strength in advance and stored at $-20^{\circ} \mathrm{C}$ in $0.5 \mathrm{ml}$ amounts for up to two months before use. In view of the carcinogenic potential of $D A B$ we recommend use of the Sigma Isopac system for preparation of stock solutions. Gloves are worn for the procedure itself and all contaminated materials are discarded into chloros at 2500 ppm available chlorine. This has the advantage of providing both a disinfectant action and an oxidant for unused DAB. The optimised DAB schedule comprised five minutes of drying followed by 10 minutes of reaction. At the end of the reaction period the chamber was dismantled, the coverslip rinsed gently in distilled water, the preparation dried in air at $37^{\circ} \mathrm{C}$, mounted in $50 \%$ glycerol and sealed with nail varnish. Mounted preparations were observed by phase contrast and brightfield microscopy; staining was assessed by the latter. Although provisional assessments could be made at a magnification $\times 600, \times 1250$ was preferred for definitive observations.

\section{Results}

Dark purple reactions were sometimes observed macroscopically when TPD was applied to heavily inoculated coverslips, but no reaction product associated with individual cells was recognisable by microscopy. No further work was done with this reagent. By contrast, DAB rapidly produced brown coloured cells with classic oxidase positive genera. Drying and reaction times of $0-20$ and 5-20 minutes were examined, respectively. Application of the DAB reagent to undried preparations yielded minimal colour even with reaction times up to 20 minutes. Neither drying beyond five minutes nor reaction times beyond 10 minutes produced appreciable enhancement of the colour. The optimised procedure (five minutes drying +10 minutes reaction) proved equally effective at demonstrating oxidase reactivity in freshly grown broth or agar cultures and agar cultures stored for up to seven days at $+4^{\circ} \mathrm{C}$.

To determine whether individual oxidase positive and negative cells could be distinguished in a single preparation, combinations of appropriate strains were examined. Coloured and uncoloured cells were readily apparent. Moreover, when the two strains were morphologically distinct, colour was only present in the appropriate cell type (figure).

The optimised DAB procedure was applied to a series of clinical isolates and laboratory strains representing both oxidase positive and negative genera (table). The microscopic oxidase reaction was consistent with the macroscopic TPD result in all cases. Very faint brown deposits were occasionally seen with Enterobacteriaceae; these were more noticeable in cell clumps. 
Bacterial strains examined with the $D A B$ oxidase procedure

\begin{tabular}{|c|c|c|c|}
\hline \multicolumn{4}{|c|}{ Macroscopic oxidase } \\
\hline Positive & $N o=$ & Negative & No $=$ \\
\hline $\begin{array}{l}\text { Pseudomonas aeruginosa } \\
\text { Pseudomonas spp } \\
\text { Agrobacterium sp } \\
\text { Neisseria meningitidis } \\
\text { Aeromonas hydrophila } \\
\text { Aeromonas sobria } \\
\text { Vibrio cholerae } \\
\text { Campylobacter jejuni } \\
\text { Bacillus cereus }\end{array}$ & $\begin{array}{l}8 \\
2 \\
1 \\
1 \\
2 \\
1 \\
1 \\
1 \\
1\end{array}$ & $\begin{array}{l}\text { Escherichia coli } \\
\text { Klebsiella spp } \\
\text { Enterobacter spp } \\
\text { Salmonella enteritidis } \\
\text { Proteus spp } \\
\text { Haemophilus influenzae } \\
\text { Haemophilus aphrophilus } \\
\text { Acinetobacter sp } \\
\text { Xanthomonas maltophilia } \\
\text { Streptococcus pyogenes } \\
\text { Staphylococcus aureus }\end{array}$ & $\begin{array}{l}9 \\
6 \\
4 \\
2 \\
2 \\
1 \\
1 \\
1 \\
3 \\
1 \\
1\end{array}$ \\
\hline
\end{tabular}

The DAB technique was applied to freshly detected positive blood cultures (Bactec, radiometric) containing Gram negative bacilli on two occasions. Dilution of the blood four or 10 -fold before centrifugation avoided excess background due to blood cell debris. The reaction was negative in both instances and subcultures subsequently yielded isolates of Escherichia coli. In each case examination of a second preparation in which a control oxidase positive strain (Pseudomonas aeruginosa) had been added to the aliquot of positive blood culture facilitated a more confident assignment of negative reactivity to the test organism.

\section{Discussion}

The cytochemical DAB oxidase reaction described requires a total processing time of under 25 minutes, assigns appropriate reactivity to individual bacterial cells and, for the organisms tested to date, produces results in accordance with the standard macroscopic technique. The exact nature of the activity demonstrated is not clearly defined but is presumably related to cytochrome $\mathrm{C}$ oxidase or its equivalents in different bacteria. Although correspondence between the DAB and macroscopic TPD techniques seems to be excellent, the many different patterns of electron transport possessed by bacteria $^{11}$ indicate that this correspondence should not be assumed for all genera.

The key factors determining feasibility of cytochemical demonstrations in the immobilised preparations used here are access of the reagents to the appropriate cell compartment and localisation of the final reaction product. Drying seems to be an essential step for access of DAB as well as the indoxyl substrate used for the $\beta$-galactosidase technique described previously. ${ }^{3}$ The reasons for this are not clear but may be related to the disruption of an outer hydrophilic barrier to reagent penetration as both reactions are diminished if cells are rehydrated again before substrate is added (Barer and Marsh, unpublished observations). The TPD reagent evidently suffers from poor localisation of the final reaction product as activity was demonstrated rapidly without drying but no colour was observed in individual cells.

Minimal non-specific reactivity was observed with some Enterobacteriaceae. This did not lead to any difficulties in interpretation and may be related to endogenous hydrogen peroxide formation and catalase activity in these organisms. ${ }^{78}$ Benzidine combined with hydrogen peroxide has been used as a reagent for the macroscopic demonstration of cyto- chrome systems in bacteria ${ }^{12}$ and a DAB based reaction for catalase has been applied to animal tissues. ${ }^{7}$ On this basis a cytochemical catalase test should also be feasible in bacteria, but technical realisation of this has eluded us so far.

It is not suggested that the DAB test should replace the conventional macroscopic oxidase test, nor that it should be used in the routine assessment of colonial growth. In the clinical context it is envisaged that this and other cytochemical techniques ${ }^{3413}$ could be used for critical specimens where the early availability of information about the organisms present, in addition to their Gram or acid fast properties, could influence subsequent patient management. Appropriate specimens could include positive blood cultures before subculture, cerebrospinal fluid, peritoneal dialysis fluid, broncho-alveolar lavage specimens and any other specimens where the choice between therapeutic options might be resolved by application of one or more cytochemical techniques. The ability of the technique to detect the correct oxidase reactivity of organisms in two blood cultures provides preliminary evidence that the presence of tissue components will not compromise its accuracy.

In conclusion, we have shown that a cytochemical DAB based technique can be used to determine the oxidase reactivity of pathogenic bacteria. Preliminary results indicate that the procedure can be applied at a stage in the processing of clinical specimens when the organisms present could only be demonstrated by microscopy in most routine laboratories. Because it does not depend on cell growth or require pure cultures, we suggest that further development of this cytochemical approach to characterising micro-organisms could provide important information that would be relevant to patient management much earlier than conventional techniques.

We thank Dr S J Pedler for access to clinical isolates from the Royal Victoria Infirmary, Newcastle upon Tyne.

1 Cowan ST, Steel KG. Manual for the identification of medical bacteria. 2nd edn. Cambridge: Cambridge University Press, 1974.

2 MacFaddin JF. Biochemical tests for identification of medical bacteria. 2nd edn. Baltimore: The Williams \& Wilkins Co., 1982

3 Barer MR. New possibilities for bacterial cytochemistry: light microscopic demonstration of $\beta$-galactosidase in unfixed immobilized bacteria. Histochem $J$ 1991;23: 529-33.

4 Barer MR, Entwistle A. Confocal microscopy of surface and cytoplasmically labelled bacteria immobilized by APScytoplasmically labelled bacteria immobilized by

5 Mudd S, Winterscheid LC, DeLamater ED, Henderson HJ. Evidence suggesting that granules of mycobacteria are mitochondria. J Bacteriol 1951;62:459-75

6 Chayen J, Bitensky L, Butcher R. Practical histochemistry. London: John Wiley, 1972:164-7.

7 Lojda Z, Gossrau R, Scheibler TH. Enzyme histochemistry. Berlin: Springer-Verlag 1979:233-8.

8 Old SL, Johnson MA. Methods of microphotometric assay of succinate dehydrogenase and cytochrome c oxidase activities for use on human skeletal muscle. Histochem $J$ 1989;21:545-55.

9 Seligman AM, Karnovsky MJ, Wasserkrug HL, Hanker JS. Non-droplet ultrastructural demonstration of cytochrome Non-droplet ultrastructural demonstration of cytochrome
oxidase activity with a polymerizing osmiophilic reagent, oxidase activity with a polymerizing osmiophilic reagen
diaminobenzidine (DAB). J Cell Biol 1968;38:1-14.

10 Robinson PJ, Dunnill P, Lilly MD. Porous glass as a solid support for immobilization or affinity chromatography of enzymes. Biochim Biophys Acta 1971;242:659-61.

11 Morris JG. The metabolism and growth of bacteria. In: Wilson GS, Dick HM, eds, Topley and Wilson's principals of bacteriology, virology and immunity. Vol I. 7th edn. London: Edward Arnold. 1984:39-69.

12 Deibel RH, Evans JB. Modified benzidine test for the detection of cytochrome-containing respiratory systems in microorganisms $J$ Bacteriol 1960;79:356-60.

13 Thom SM, Barer MR. Cytochemical tests of bacterial viability. Abstracts of the 162nd meeting of the Pathological Society of Great Britain and Ireland. J Med Microbiol 1991;34:iv. 